\title{
Mobilidade populacional e educação superior no norte do Estado do Rio de Janeiro
}

Population movements and higher education in the North of Rio de Janeiro

Mobilité de la population et enseignement supérieure au Nord de l'état de Rio de Janeiro

Movilidad poblacional y educación superior en el Norte del Estado de Río de Janeiro

Jéssica Monteiro da Silva Tavares e Elzira Lucia de Oliveira

\section{(2) OpenEdition}

\section{Journals}

\section{Edição electrónica}

URL: http://journals.openedition.org/espacoeconomia/2335

DOI: $10.4000 /$ espacoeconomia.2335

ISSN: 2317-7837

\section{Editora}

Núcleo de Pesquisa Espaço \& Economia

\section{Refêrencia eletrónica}

Jéssica Monteiro da Silva Tavares e Elzira Lucia de Oliveira, « Mobilidade populacional e educação superior no norte do Estado do Rio de Janeiro », Espaço e Economia [Online], 9 | 2016, posto online no dia 19 janeiro 2017, consultado o 24 março 2020. URL : http://journals.openedition.org/ espacoeconomia/2335; DOI : https://doi.org/10.4000/espacoeconomia.2335 


\section{Mobilidade populacional e educação superior no norte do Estado do Rio de Janeiro}

Population movements and higher education in the North of Rio de Janeiro

Mobilité de la population et enseignement supérieure au Nord de l'état de Rio de Janeiro

Movilidad poblacional y educación superior en el Norte del Estado de Río de Janeiro

Jéssica Monteiro da Silva Tavares e Elzira Lucia de Oliveira

\section{Introdução}

1 Embora o principal motivo dos deslocamentos pendulares seja a procura por trabalho, a busca por oportunidades educacionais também é motivação de deslocamentos populacionais. O padrão espacial da localização dos estabelecimentos de ensino, de forma concentrada em determinados espaços, para níveis de ensino médio e superior, leva à necessidade de deslocamentos frequentes entre residência e unidade de ensino por parte de um amplo número de estudantes. Desse modo, o objetivo geral deste trabalho é analisar os movimentos pendulares de estudantes de nível superior na região Norte Fluminense, principalmente em direção à Campos dos Goytacazes. Além de identificar os fluxos de origem, identificar-se-á também, de forma resumida, o perfil desses estudantes pendulares. Para entender a centralidade do município de Campos dos Goytacazes na oferta de serviços de ensino, será calculado o Quociente Locacional (QL) no setor de ensino dos municípios da região, bem como dos municípios classificados pelo IBGE no mesmo nível de hierarquia urbana de Campos dos Goytacazes. Adicionalmente, foi calculado o Índice de Eficácia da Pendularidade (IE) para os municípios da região Norte fluminense. 
O recorte espacial deste estudo, a região Norte do estado do Rio de Janeiro, tem passado por profundas modificações socioeconômicas e territoriais após a descoberta e exploração de petróleo na Bacia de Campos. O município de Macaé, base operacional da Petrobrás, quadruplicou, passando de 47.221 habitantes em 1970 para 206.728 em 2010. $\mathrm{O}$ adensamento populacional e a valorização do solo urbano têm espraiado os efeitos da indústria petrolífera para os municípios limítrofes, como também tem produzido fluxos diários entre vários municípios da região e Macaé, em decorrência da grande oferta de trabalho.

Por outro lado, a busca por qualificação, visando em grande parte inserção na indústria petrolífera, também tem gerado fluxos entre os municípios, especialmente com destino à Campos dos Goytacazes, que mantém uma oferta regular de ensino profissionalizante de nível médio e nível superior, por meio de instituições públicas e privadas. Adicionalmente, os recursos de royalties e participações especiais que os municípios impactados direta e indiretamente pela indústria do petróleo recebem, conferem a esses municípios certa folga orçamentária em relação aos demais, com poucas restrições em relação à alocação desses recursos. Sendo assim, os municípios contemplados com esses recursos, especialmente os menores, na ausência de oferta de serviços educacionais no local, fornecem bolsas de estudos e transporte para os residentes estudarem em outro município, geralmente em Campos dos Goytacazes, em função de uma oferta diferenciada na região ${ }^{1}$.

Este trabalho é de natureza predominantemente quantitativa e descritiva e utiliza como fonte dados o Censo Demográfico do Instituto Brasileiro de Geografia e Estatística (IBGE) de 2010, o Censo Escolar e o Censo da Educação Superior do Instituto Nacional de Estudos e Pesquisas Educacionais Anísio Teixeira (INEP).

5 A figura 1 apresenta uma síntese da abordagem desse estudo, situando o fenômeno da pendularidade no âmbito da discussão do conceito mais amplo de mobilidade populacional, destacando a mobilidade territorial da população e o foco deste estudo, os deslocamentos pendulares em busca de oportunidades educacionais na região Norte Fluminense.

Figura 1 - Esquema sintético da proposta do estudo

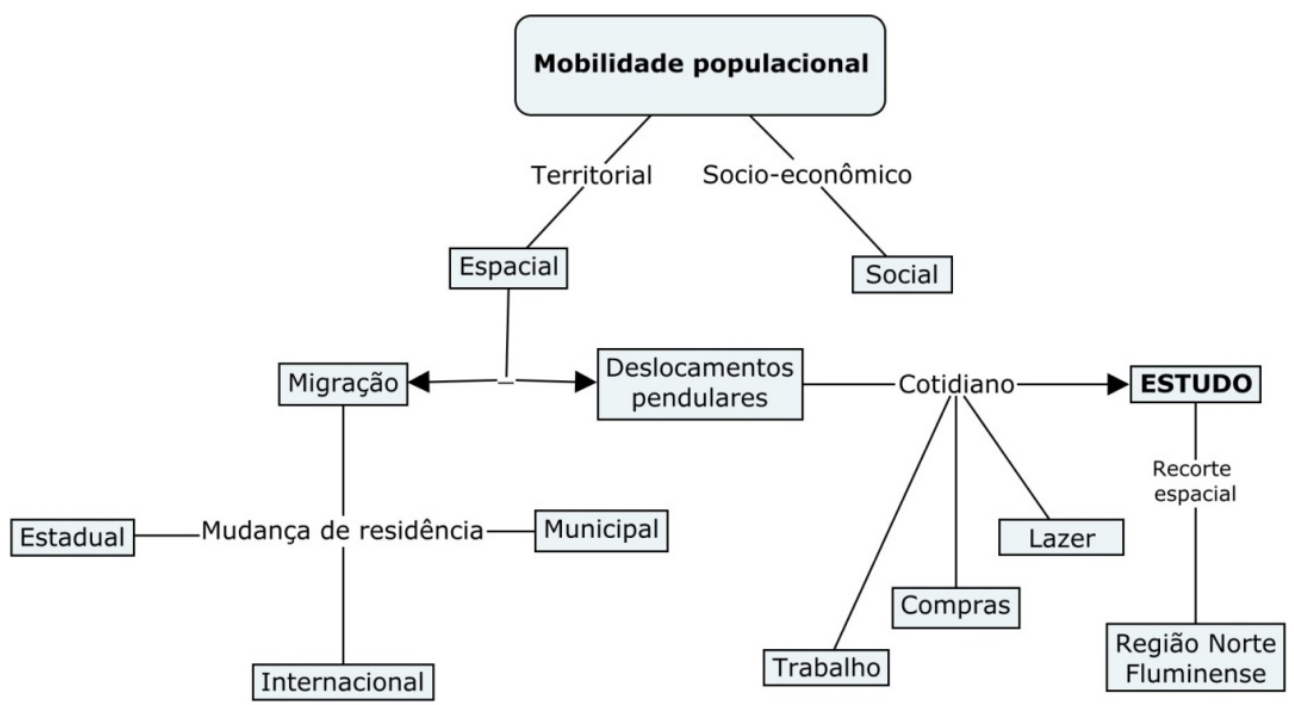

Fonte: Elaboração própria. 
Após essa breve introdução, serão discutidos na seção dois os aspectos conceituais de mobilidade espacial da população em geral e movimentos pendulares em particular; na seção três apresenta os procedimentos metodológicos; na seção quatro apresenta os resultados; na quinta apresenta as considerações finais.

\section{Mobilidade Espacial: Migração e Movimentos Pendulares}

7 A mobilidade espacial se refere à capacidade de se mover no espaço. Esse fenômeno, pode envolver tanto a migração, considerada a mudança do lugar de residência, como os movimentos diários, entre os quais os mais conhecidos são os movimentos chamados de pendulares ${ }^{2}$

Apesar dos movimentos migratórios e deslocamentos pendulares produzirem fluxos de pessoas pelo território, a essência desses movimentos é diferente. No que tange às definições, Patarra e Cunha (1987) destacam a complexidade do fenômeno:

sob um conceito amplo e mal definido, mesclam-se processos complexos e diversificados, que emergem na resultante redistribuição da população no espaço. Desde mudanças de residência relacionadas a momentos do ciclo vital até movimentos que significam etapas de ascensão na escala social, diversos e complexos são os fatores subjacentes aos deslocamentos populacionais de uma área a outra ${ }^{3}$.

Cunha (2012) reafirma essa complexidade ressaltando as múltiplas dimensões da mobilidade espacial da população: "Sendo a migração, ou mais genericamente, a mobilidade espacial da população um fenômeno multifacetado e, principalmente, multiescalar, sua definição nem sempre é imediata e óbvia" 4

Em meio às várias definições, Carvalho e Rigotti ${ }^{5}$ afirmam que o conceito de migração não inclui os deslocamentos que as pessoas não se fixam de forma permanente no local de destino. Sendo assim, "os movimentos sazonais, temporários, e os de populações nômades não são considerados migração", assim como os movimentos pendulares.

De acordo com Adan (1994) ${ }^{6}$, o conceito de mobilidade refere-se à vida cotidiana do indivíduo, que, segundo os autores, recebe a denominação de mobilidade pendular, sendo entendida como "[...] conjunto de deslocamentos que o indivíduo efetua para executar os atos de sua vida cotidiana (trabalho, compras, lazer). "Sendo assim, os deslocamentos do tipo pendular fazem parte da distribuição da população pelo espaço, em seus múltiplos aspectos, cujas modalidades estão inter-relacionadas, a partir das migrações internas, da mobilidade residencial, da mobilidade cotidiana e ao espaço de vida, que é o espaço no qual o indivíduo realiza todas suas atividades ${ }^{7}$.

Sobre a mobilidade pendular há, ainda, abordagens relacionadas a diferentes objetivos (no que tange a orientação de políticas públicas, orientação na alocação de investimentos urbanos, suas implicações sobre impactos simbólicos e de desgastes físicos dos atores, etc.); abordagens relacionadas a diferentes escalas (intermunicipais, interestaduais e internacionais) e dimensões (deslocamentos centrados em postos de trabalho, serviços públicos de saúde ou educação). Enfim, são muitas as questões relacionadas à mobilidade pendular ${ }^{8}$.

12 Segundo o Dicionário Demográfico Multilíngue a migração envolve mudança no local de residência habitual e implica em movimento que ultrapassa uma fronteira administrativa, enquanto a mobilidade pendular envolve jornada diária ou semanal do 
local de residência para o local de realização de sua atividade, geralmente trabalho ou estudo9. Moura (2005) ${ }^{10}$ considera as diferenças conceituais de forma similar: "enquanto a migração envolve mudança de residência, os deslocamentos pendulares caracterizamse por deslocamentos entre o município de residência e outros municípios, com finalidade específica". Outro ponto que é ressaltado pelas autoras é a diferença da natureza dos movimentos pendulares e migratórios, apesar de ambos envolverem o fluxo de pessoas pelo território. Nessa linha de pensamento, Cunha (2012) afirma que em função das características do movimento pendular - movimento diário sem caráter permanente -, o fenômeno não deve ser classificado como migração, e sim, como um tipo de mobilidade populacional.

Segundo Pereira (2006), o movimento pendular deve ser considerado como um deslocamento funcional e não residencial em que, havendo a existência de um local intermediário, a origem e o destino final dos deslocamentos são os mesmos.

Outra relação que se pode estabelecer entre migração e movimentos pendulares, é a de que os movimentos pendulares funcionam, muitas vezes, como alternativa à migração, retendo a população potencialmente migrante. Diante das opções de migrar ou da possibilidade de realizar movimento diário (viabilizada por circunstâncias favoráveis como boas condições de infraestrutura, acesso aos meios de transporte e custos aceitáveis de deslocamento) esses indivíduos optam por realizar o movimento cotidiano a mudar de forma definitiva de local de residência, diminuindo assim os fluxos migratórios ${ }^{11}$. Considerando que essa mobilidade cotidiana da população é de grande relevância para se compreender as transformações socioeconômicas correntes, deve-se considerar a diversidade do uso do termo que aparece nos trabalhos acadêmicos ora como migração pendular, ora como movimento pendular e até deslocamento pendular. Beaujeu-Garnier (1980), denomina os movimentos pendulares de "migrações oscilatórias" que, se tiverem duração prolongada são chamadas de migrações de temporada, enquanto os movimentos de curto período são denominados de cotidianos e as pessoas que o realizam, migrantes diários. Ravenstein (1985) designa "migrantes temporários"; Castells (1972), por sua vez, denominou de "migrações alternantes"; o termo americano é o commuting, enquanto os franceses denominam de navettes. Esses termos, são associados aos deslocamentos cotidianos realizados pela população. Notase, portanto, que não há uma denominação única para esse tipo de deslocamento.

Para este trabalho, optou-se pelo uso dos termos deslocamento ou movimento pendular por se entender que se tratam de movimentos cotidianos com uma determinada periodicidade que não resultam, a priori, em transferência definitiva de residência.

Quanto à duração dos deslocamentos, Jardim (2011) ${ }^{12}$ sugere que a mobilidade pendular envolve distintas dimensões e diversas práticas cotidianas da população no território referentes à mudança de lugar, referindo-se aos "percursos entre o domicílio e o lugar de trabalho, medidos em termos de tempo e espaço, que pode variar de uma hora ou mais, um dia de trabalho, uma semana ou um mês". Cabe ressaltar que mais do que mudança de lugar, do ponto de vista puramente demográfico, a mobilidade pendular deve ser também analisada do ponto de vista social. Muda-se de lugar, mas não se perde o vínculo preexistente com o outro território, já que nessa dimensão temporal, esse tipo de deslocamento apresenta a tipicidade de uma frequência cotidiana.

17 Apesar de ainda não haver um consenso sobre a escala espacial de um deslocamento para que ele seja considerado pendular, existem algumas abordagens diferenciadas entre os pesquisadores. O fenômeno captado pelos Censos Demográficos e classificado 
como 'deslocamento pendular' considera apenas deslocamentos intermunicipais sejam nacionais ou internacionais. Essa abordagem também está presente nos trabalhos de Golgher (2004); Antico (2004); Fernandes e Vasconcelos (2004). Em trabalhos como o de Cunha (2002), Cunha et al. (2006), Pereira (2006) e Lima (2015) são utilizadas a mesma categoria, contemplando, porém, tanto deslocamentos intermunicipais como intramunicipais, considerando as trocas populacionais constantes entre diferentes bairros do mesmo município.

\section{Configuração Regional Recente}

Cronologicamente, destacam-se duas importantes fases da economia da região Norte Fluminense: a indústria sucroalcooleira e a indústria petrolífera. $\mathrm{O}$ advento de petróleo na plataforma continental da Bacia de Campos influencia diretamente a economia de vários municípios do Norte Fluminense por meio dos significativos recursos dos royalties e participações especiais para as receitas municipais.

19 A consolidação da indústria do petróleo produziu uma competição para localização no espaço regional, enquanto Macaé era lócus privilegiado das empresas da cadeia produtiva da Indústria de Extração e Produção de Petróleo e Gás, Campos consolidou a tradição de polo regional de ensino, tanto superior quanto técnico, ofertado em instituições públicas e privadas.

A diversidade da oferta de ensino em Campos nos níveis médio, técnico e superior, em diferentes tipos de estabelecimento como universidades, centros universitários, faculdades e institutos federais, atraem estudantes não só da região Norte Fluminense e adjacências, como também de outros estados como Minas Gerais e Espírito Santo. Entre essas instituições, citam-se: Universidade Estadual Norte Fluminense Darcy Ribeiro (UENF), Universidade Federal Fluminense (UFF), Instituto Federal Fluminense (IFF), Instituto Superior de Educação Professor Aldo Muylaert (ISEPAM), Universidade Estácio de Sá (UNESA), Faculdade de Direito de Campos (FDC), Faculdade de Medicina de Campos (FMC), Faculdade de Odontologia de Campos (FOC), Faculdade de Filosofia de Campos (FAFIC), Universidade Cândido Mendes (UCAM), Universidade Saldado de Oliveira (UNIVERSO), Institutos Superiores de Ensino do Centro Educacional Nossa Senhora Auxiliadora (ISECENSA) além do campus da Universidade Federal Rural do Rio de Janeiro (UFRRJ) que atua apenas como centro de apoio ao ensino, à pesquisa e à extensão agropecuária nas regiões Norte e Noroeste Fluminense, no estado do Espírito Santo, nordeste de Minas Gerais e no sul da Bahia, não ofertando assim, cursos com alunos matriculados.

21 A indústria petrolífera é o motor do desenvolvimento do Norte Fluminense, principalmente quando se trata de qualificação da mão de obra, pois a região transitou da monocultura canavieira que exige baixa qualificação de mão de obra, para uma atividade econômica com crescente incorporação de progresso técnico, exigindo, portanto, qualificação profissional.

De acordo com os microdados do Censo da Educação Superior (2015), dos nove municípios da região Norte Fluminense, apenas quatro contam com instituições de ensino superior: Campos, Macaé, Quissamã e São Fidélis, sendo que a maioria delas se concentra em Campos dos Goytacazes. 


\section{Dinâmica populacional recente}

Em que pese a concentração da população do Estado na Região Metropolitana do Rio de Janeiro, assiste-se a uma queda dessa participação de 80,22\% em 2000 para 76,87\% em 2010. Em contrapartida, com exceção das regiões Noroeste e Centro, todas as demais ganham participação. Observa-se que o crescimento populacional do estado do Rio de Janeiro na década de 2010 acompanha o nível de crescimento verificado para o Brasil e para a região Sudeste, em torno de 1,0\% ao ano. Contudo, o crescimento das mesorregiões Norte $(1,95 \%)$ e principalmente das Baixadas, que apresentou crescimento médio anual de $4,16 \%$, se destacam das demais com grandes taxas de crescimento, sendo inclusive maiores do que a apresentada pela região Metropolitana, o que demonstra que o ritmo de crescimento populacional desta é menos intenso do que o ritmo de crescimento das Baixadas, do Norte e até do Sul Fluminense, apesar da região Metropolitana ainda concentrar a população do estado (tabela 1).

Tabela 1

Participação percentual na população do Rio de Janeiro por unidades territoriais selecionadas $2000-2010$

\begin{tabular}{|l|l|l|}
\hline \multirow{2}{*}{ Unidades territoriais } & \multicolumn{2}{|l|}{ Participação percentual na população do Rio de Janeiro } \\
\cline { 2 - 4 } & 2000 & 2010 \\
\hline Metropolitana do Rio de Janeiro & 80,22 & 78,67 \\
\hline Sul Fluminense & 6,49 & 6,64 \\
\hline Norte Fluminense & 4,86 & 5,31 \\
\hline Campos dos Goytacazes & 3,65 & 3,68 \\
\hline Macaé & 1,21 & 1,64 \\
\hline Baixadas Litorâneas & 3,21 & 4,38 \\
\hline Rio das Ostras & 0,25 & 0,66 \\
\hline Centro Fluminense & 3,15 & 3,01 \\
\hline Noroeste Fluminense & 2,07 & 1,99 \\
\hline
\end{tabular}

Fonte: Elaboração própria a partir dos dados do Censo Demográfico 2010 (IBGE,2010)

24 O município de Campos dos Goytacazes é considerado pelo IBGE, como uma Área de Concentração de População (ACP) definidas como:

Grandes manchas urbanas de ocupação contínua, caracterizadas pelo tamanho e densidade da população, pelo grau de urbanização e pela coesão interna da área, dada pelos deslocamentos da população para trabalho ou estudo ${ }^{13}$. 
No Brasil existem 40 ACPs, constituídas por agregação de 336 municípios. No estado do Rio de Janeiro são apenas três: Rio de Janeiro, Campos dos Goytacazes e Volta RedondaBarra Mansa. Campos compõe a rede urbana comandada pela metrópole (Rio de Janeiro), classificada como capital regional C, que na hierarquia dos centros urbanos representa um nível

com capacidade de gestão no nível imediatamente inferior ao das metrópoles, têm área de influência de âmbito regional, sendo referidas como destino, para um conjunto de atividades, por grande número de municípios. (...) Além da diferenciação de porte, têm padrão de localização regionalizado ${ }^{14}$.

\section{Demanda por educação}

De acordo com o IBGE, em 2010, Campos apresentou 145.898 alunos matriculados em todos os níveis de ensino. A tabela 2 apresenta o total de estudantes no nível superior em 2010, segundo os dados do Censo Demográfico. Campos apresenta o maior contingente de estudantes em números absolutos, contudo em termos percentuais é o que apresenta o menor percentual de estudantes que se deslocam diariamente para estudar em outro município (7\%), evidenciando que a oferta diferenciada de cursos superiores no município atende de forma satisfatória a população de estudantes residentes. Com exceção do município de Macaé, onde o percentual de estudantes pendulares é de $19,2 \%$, todos os demais municípios da região apresentam percentual superior a $60 \%$. Em termos regionais, verifica-se que $21,2 \%$ dos estudantes são pendulares, ou seja, frequenta instituição de nível superior em outro município.

Tabela 2

Total de estudantes do Ensino Superior e estudantes pendulares no Ensino Superior, região Norte Fluminense e municípios - 2010

\begin{tabular}{|l|l|l|l|}
\hline Municípios & $\begin{array}{l}\text { Total de alunos na } \\
\text { graduação }\end{array}$ & $\begin{array}{l}\text { Deslocamento para cursar } \\
\text { graduação }\end{array}$ & $\begin{array}{l}\text { Deslocamentos sobre total } \\
\text { de alunos (\%) }\end{array}$ \\
\hline Carapebus & 299 & 268 & 89,4 \\
\hline $\begin{array}{l}\text { Campos dos } \\
\text { Goytacazes }\end{array}$ & 14.687 & 1.029 & 7,0 \\
\hline Cardoso Moreira & 301 & 288 & 95,5 \\
\hline $\begin{array}{l}\text { Conceição de } \\
\text { Macabu }\end{array}$ & 443 & 434 & 98,0 \\
\hline Macaé & 7.705 & 1.477 & 19,2 \\
\hline Quissamã & 624 & 390 & 62,4 \\
\hline $\begin{array}{l}\text { São F. de } \\
\text { Itabapoana }\end{array}$ & 797 & 516 & 64,7 \\
\hline São Fidélis & 923 & 567 & \\
\hline
\end{tabular}




\begin{tabular}{|l|l|l|l|}
\hline São João da Barra & 703 & 634 & 90,1 \\
\hline $\begin{array}{l}\text { Região Norte } \\
\text { Fluminense }\end{array}$ & 26.482 & 5.602 & 21,2 \\
\hline
\end{tabular}

Fonte: Elaboração própria a partir dos dados do Censo Demográfico 2010 (IBGE,2010)

27 Dados mais recentes, do Censo da Educação Superior (2014) divulgados pelo INEP este ano, indicam que o número total de estudantes matriculados nos cursos de graduação em Campos supera os 18 mil alunos (18.062). O Censo da Educação Superior é realizado anualmente, enquanto o período de realização do Censo Demográfico (realizado pelo IBGE) é decenal.

28 Cabe ressaltar que existe uma diferença na forma de obtenção dos dados. No Censo Demográfico, as perguntas são feitas diretamente ao indivíduo, que responde por todas as pessoas residentes em seu domicílio. Já no Censo da Educação Superior, os dados são coletados a partir do preenchimento dos questionários, por parte das Instituições de Ensino Superior (IES) e por importação de dados do Sistema eletrônico do Ministério da Educação (MEC). Sendo assim, pode haver divergências com relação ao mesmo tipo de dado em um mesmo ano, pois as fontes de informação são diferentes.

\section{Nível de centralidade no ensino de graduação no Brasil}

O IBGE realizou uma pesquisa sobre o nível de centralidade no ensino de graduação no Brasil e identificou que no nível mais alto de centralidade na graduação (nível 1), encontram-se apenas duas cidades: Rio de Janeiro e São Paulo, as maiores metrópoles do país. No segundo nível, foram identificados nove centros e 21 no terceiro nível. Campos dos Goytacazes é uma das 33 cidades que estão no quarto nível de centralidade no ensino de graduação do país, o que lhe confere papel de polo educacional regional. ${ }^{15}$

A figura 2 apresenta o mapa com a espacialização dos seis níveis de centralidade no ensino superior identificados pelo REGIC (2007).

Figura 2 
Distribuição espacial do ensino de graduação no Brasil por níveis de centralidade (2008)

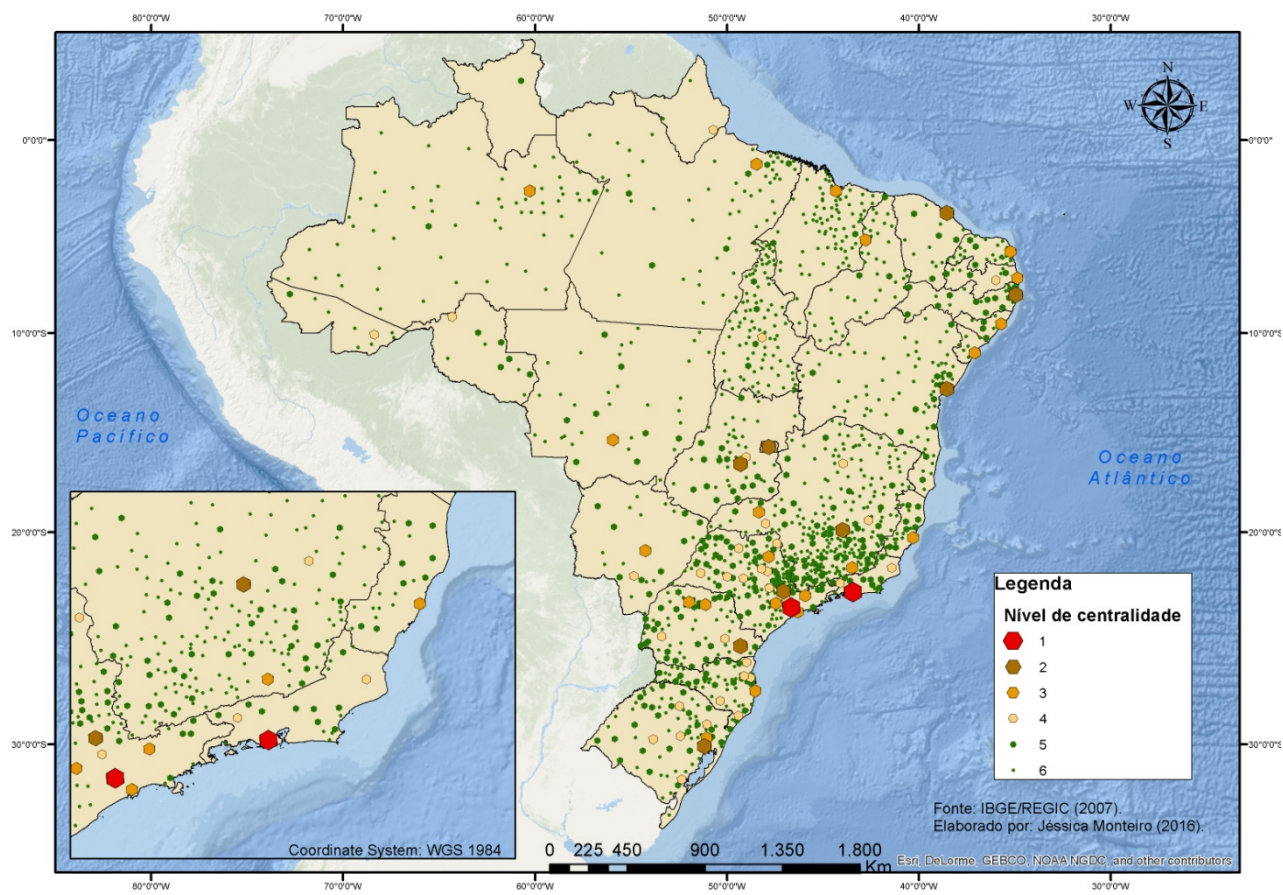

Fonte dos dados: Elaboração própria a partir dos dados do REGIC, 2007 (IBGE,2008)

\section{Distribuição espacial da população e das Instituições de Ensino Superior}

31 A figura 3 apresenta a distribuição espacial da população de 19 a 29 anos (considerada neste trabalho como aquela com idade adequada à frequência ao nível superior) e das IES nos municípios da região Norte Fluminense.

Observa-se que a população alvo se concentra em números absolutos nos municípios de Campos e Macaé e em menor número em Carapebus e Cardoso Moreira. Com relação às IES, há uma concentração geográfica nos municípios de Campos, que conta com 20 instituições e Macaé, com 21 IES. Os municípios de Macaé, São Fidélis e São Francisco de Itabapoana, também atuam como polos presenciais de educação à distância do Consórcio CEDERJ (Centro de Educação Superior a Distância do Estado do Rio de Janeiro). A educação a distância se coloca como uma opção para aqueles sem oportunidades de acesso ao ensino superior, principalmente o ensino público, por residirem longe das IES ou até mesmo por indisponibilidade de tempo nos horários tradicionais de aula presenciais.

Figura 3 
Distribuição espacial da população de 19 a 29 anos e das instituições de Ensino Superior na região Norte Fluminense

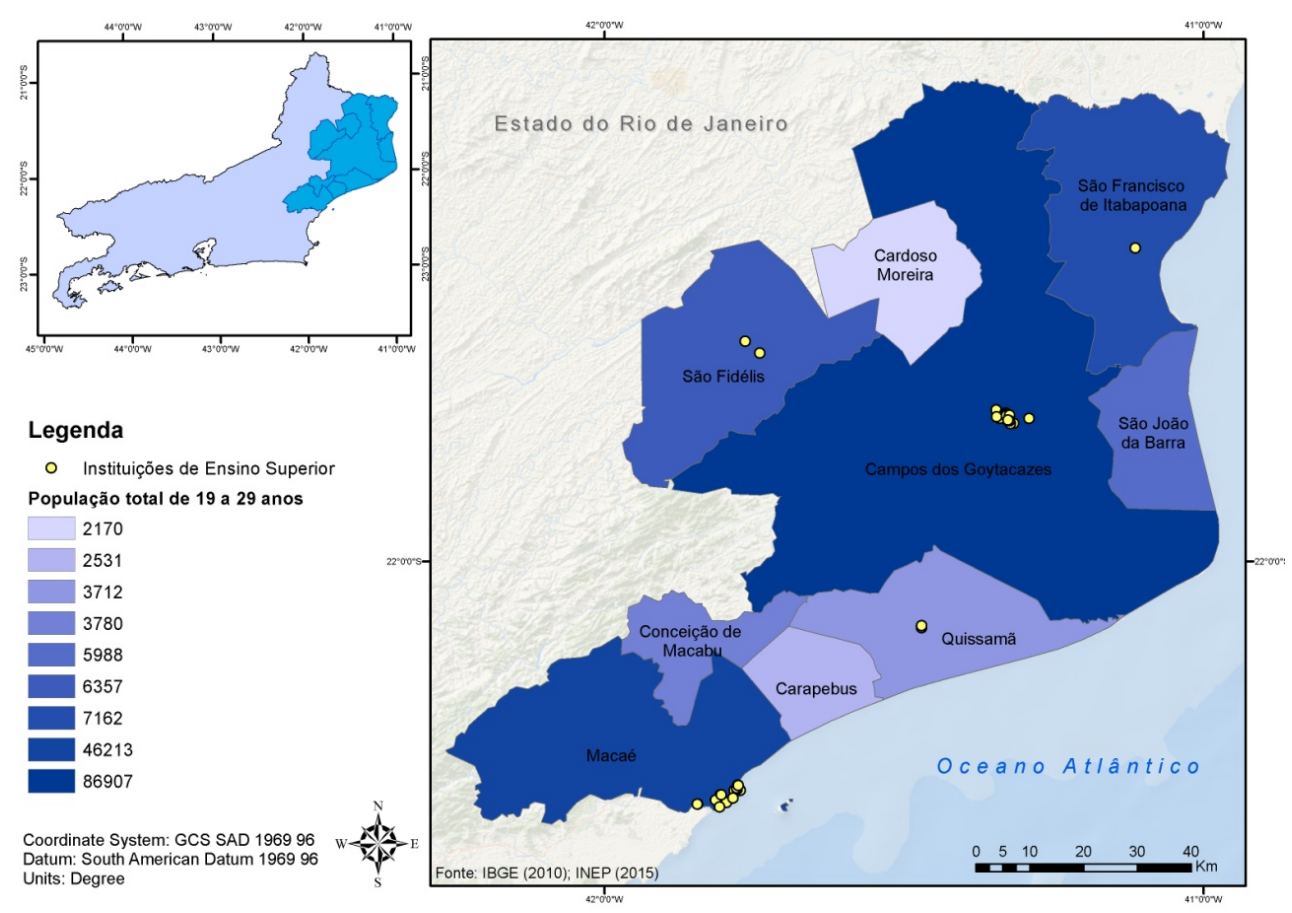

Fonte: IBGE (2010), INEP (2015). Elaboração própria.

Por fatores relacionados à restrição de oferta em alguns municípios, fica evidente que, para cursar o ensino superior, muitos estudantes precisam se deslocar de seus municípios de residência. A busca por um curso específico de seu interesse, principalmente no setor de petróleo e gás, também influencia na decisão de deslocar para estudar.

\section{Metodologia}

As fontes de dados utilizadas foram o Censo Demográfico do IBGE de 2010 e do Censo da Educação Superior do INEP e os dados de emprego formal da Relação Anual de Informações Sociais (RAIS) de 2010.

Por meio das fontes utilizadas identificou-se os movimentos dos estudantes entre os municípios da região. A análise com foco nos indivíduos traçou o perfil dos estudantes pendulares em relação às seguintes variáveis: instituição de ensino (pública ou privada), estrutura etária, sexo, município de origem e renda familiar per capita. 0 índice de eficácia da pendularidade e o quociente locacional foram estimados.

O Índice de Eficácia de Pendularidade (IE) mostra a relação entre entrada e saída da população (no caso deste estudo, de estudantes). O IE para cada município das regiões selecionadas foi calculado a partir da fórmula seguinte: 


$$
I E=\frac{(E-S)}{(E+S)}
$$

Em que $\mathrm{E}$ é igual ao número de pessoas que entram no município para estudar e, $\mathrm{S}$ representa o número de pessoas que saem do município para estudar.

O IE varia entre - 1 e 1 e quanto mais próximo de 1, maior a capacidade de absorção de estudantes do município e, quando mais o valor se aproxima de -1, maior evasão de estudantes do município. Valores próximos de zero indicam rotatividade migratória, isto é, áreas que apresentam fluxos semelhantes de entrada e saída de pessoas ${ }^{16}$.

Com o objetivo de medir a especialização dos municípios no setor educacional o Quociente Locacional (QL) foi mensurado para Campos dos Goytacazes em três níveis (regional, estadual e nacional), expresso pela fórmula seguinte:

$$
\begin{aligned}
& Q L_{i j}=\frac{\frac{E_{i j}}{\sum_{j} E_{i j}}}{\frac{\sum_{i} E_{i j}}{\sum_{i} \sum_{j} E_{i j}}} \\
& \text { Sendo: } \\
& E_{i j} \quad \begin{array}{l}
\text { Ocupado no setor } i \text { (nesse caso, o setor } \\
\text { educacional), na região } j
\end{array} \\
& \sum_{i} E_{i j} E_{i j} \quad \text { Ocupados na região j }
\end{aligned}
$$

40 Se o valor do QL for maior que a unidade, significa que a importância do setor na região frente à economia como um todo é maior do que a importância do conjunto dos setores dessa região frente essa mesma economia.

\section{Resultados}

As instituições de ensino do Norte Fluminense atendem à grande parte da população estudantil da região Noroeste, de outras regiões do estado e até de outros estados. A figura 4 apresenta o volume de entrada de estudantes (de todas as idades e níveis de ensino) nos municípios das regiões Norte, Noroeste e Baixadas Litorâneas. 0 volume de entrada é uma expressão da atratividade dos municípios no que se refere às oportunidades educacionais, para todos os níveis de ensino.

Itaperuna, no Noroeste do estado; Cabo Frio, nas Baixadas Litorâneas e Campos, no Norte Fluminense estão entre os que recebem um maior contingente de estudantes. Macaé, também no Norte Fluminense aparece na quarta colocação, contudo é Campos que recebe o maior volume de estudantes em busca de qualificação: 8.532 pessoas vindas de outros municípios. Além de ser indicador de oferta de vagas, esse dado também indica a demanda por educação por parte de alguns municípios e a centralidade exercida por Campos nessa região. 
Figura 4

Municípios das regiões Norte, Noroeste e Baixadas litorâneas, segundo atração de estudantes de outros municípios para estudo (2010)

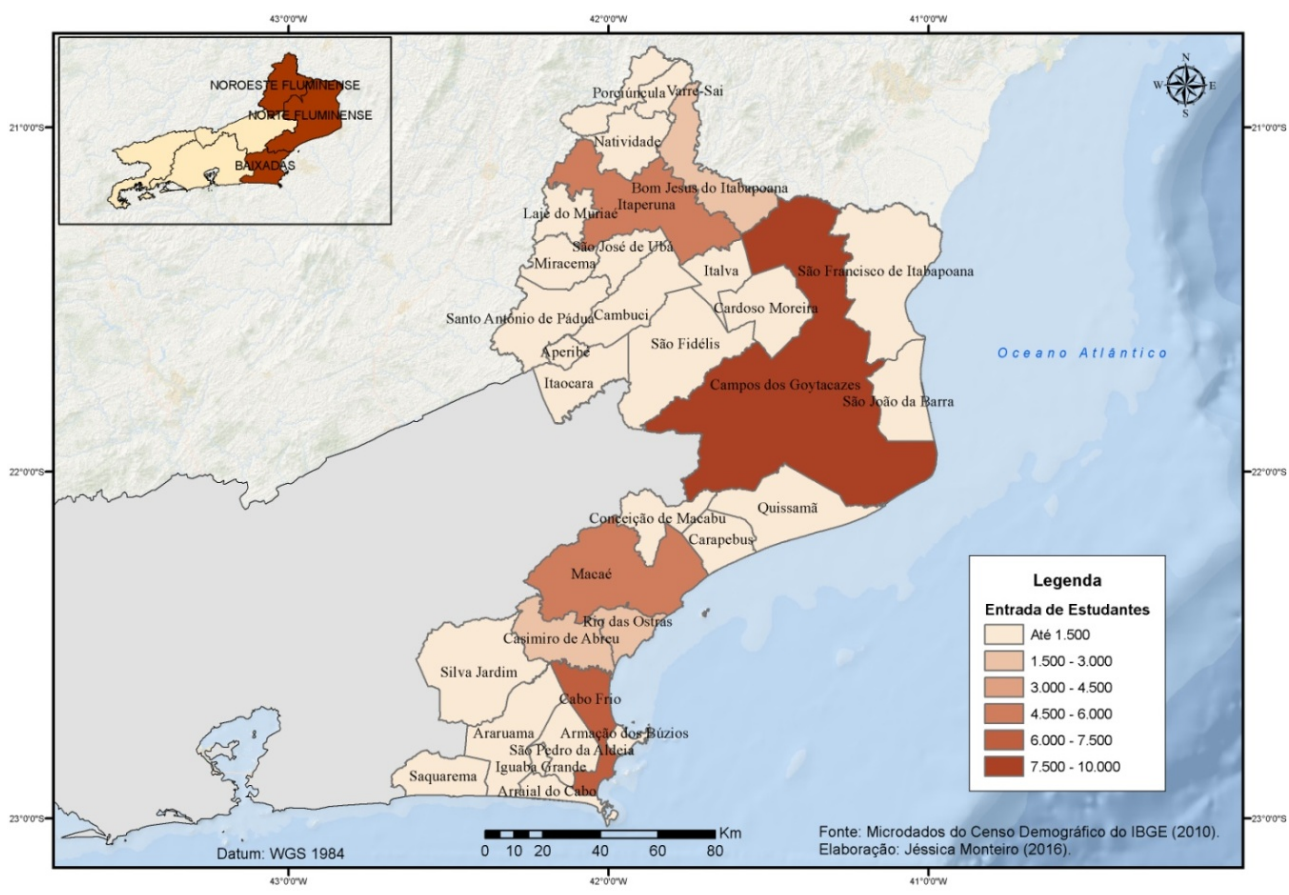

Fonte: Elaboração a partir dos microdados do Censo Demográfico 2010 (IBGE, 2010)

Com relação ao local de residência desses estudantes que realizam deslocamento pendular, a tabela 3 indica os 15 municípios do Brasil que dão origem aos movimentos de estudantes em direção à Campos. Entre eles, vale ressaltar a presença de estudantes do estado do Espírito Santo, com dois municípios diferentes (Mimoso do Sul e Cachoeiro de Itapemirim). Os três primeiros (São João da Barra, São Francisco de Itabapoana e São Fidélis) são vizinhos territoriais, fazendo fronteira com Campos, o que facilita e potencializa o deslocamento nessa direção. Destaca-se também a presença de estudantes oriundos do município do Rio de Janeiro que, apesar de ser uma grande metrópole com ampla oferta educacional, contribui com $8,8 \%$ do total entradas de estudantes em Campos.

Tabela 3

Entrada de estudantes em Campos dos Goytacazes segundo município de residência - Brasil (2010)

\begin{tabular}{|l|l|l|l|l|}
\hline Municípios/UF de residência & Estudantes & $\begin{array}{l}\% \text { sobre o total de } \\
\text { pendulares }\end{array}$ & $\begin{array}{l}\% \text { sobre o total de } \\
\text { matrículas }\end{array}$ \\
\hline São João da Barra/RJ & 1.042 & 12,2 & 0,7 \\
\hline $\begin{array}{l}\text { São Francisco de Itabapoana/ } \\
\text { RJ }\end{array}$ & 791 & 9,3 & 0,5 \\
\hline
\end{tabular}




\begin{tabular}{|c|c|c|c|}
\hline São Fidélis/RJ & 758 & 8,9 & 0,5 \\
\hline Rio de Janeiro/RJ & 750 & 8,8 & 0,5 \\
\hline Macaé/RJ & 622 & 7,3 & 0,4 \\
\hline Quissamã/RJ & 261 & 3,1 & 0,2 \\
\hline Italva/RJ & 250 & 2,9 & 0,2 \\
\hline Cardoso Moreira/RJ & 249 & 2,9 & 0,2 \\
\hline Bom Jesus do Itabapoana/RJ & 238 & 2,8 & 0,2 \\
\hline São Gonçalo/RJ & 210 & 2,5 & 0,1 \\
\hline Mimoso do Sul/ES & 207 & 2,4 & 0,1 \\
\hline Itaperuna/RJ & 185 & 2,2 & 0,1 \\
\hline Cachoeiro de Itapemirim/ES & 178 & 2,1 & 0,1 \\
\hline Cambuci/RJ & 167 & 2,0 & 0,1 \\
\hline Conceição de Macabu/RJ & 137 & 1,6 & 0,1 \\
\hline Outros & 2.485 & 29,1 & 1,7 \\
\hline $\begin{array}{l}\text { Total de estudantes } \\
\text { pendulares }\end{array}$ & 8.530 & 100,0 & - \\
\hline $\begin{array}{l}\text { Total de matrículas em } \\
\text { Campos }\end{array}$ & 145.898 & - & - \\
\hline
\end{tabular}

Fonte: Elaboração própria a partir dos dados do Censo Demográfico 2010 (IBGE, 2010)

Da população residente nos municípios da região Norte Fluminense, 261.822 declararam frequentar escola ou creche, sendo que $96,1 \%$ deles estudam no município de residência. Os que estudam em outro município correspondem a 3,8\% e os que estudam em país estrangeiro são 85 pessoas, em números absolutos, representam menos de 0,1\% do total, conforme tabela 4 , a seguir.

Tabela 4

Distribuição dos estudantes da região Norte Fluminense segundo o lugar de frequência à escola (2010)

\begin{tabular}{|l|l|l|}
\hline Local & Total & Percentual (\%) \\
\hline Município de residência & 251.663 & 96,1 \\
\hline Outro município & 10.073 & 3,8 \\
\hline
\end{tabular}




\begin{tabular}{|l|l|l|}
\hline País estrangeiro & 85 & 0,1 \\
\hline Total & 261.822 & 100,0 \\
\hline
\end{tabular}

Fonte: Elaboração própria a partir dos dados do Censo Demográfico 2010 (IBGE, 2010)

Das 10.073 pessoas que declararam frequentar escola ou creche em outro município, 4,8\% cursam a educação infantil (creche, pré-escola e classe de alfabetização); 21,7\% cursam o ensino fundamental (Alfabetização de jovens e adultos, regular e EJA), 18,4\% estão no ensino médio (regular e EJA), 47,3\% cursam o ensino superior e 7,8\% frequentam a pós-graduação Lato Sensu (especialização) e Stricto Sensu (mestrado e doutorado) (tabela 5).

Tabela 5

Nível de curso que os estudantes pendulares da região Norte Fluminense frequentam (2010).

\begin{tabular}{|l|l|l|}
\hline Curso que frequenta & Total de estudantes & Percentual (\%) \\
\hline Educação Infantil & 487 & 4,8 \\
\hline Ensino Fundamental & 2.184 & 21,7 \\
\hline Ensino Médio & 1.851 & 18,4 \\
\hline Ensino Superior & 4.762 & 47,3 \\
\hline Pós-graduação (Lato e Stricto Sensu) & 790 & 7,8 \\
\hline Total & 10.073 & 100,0 \\
\hline
\end{tabular}

Fonte: Elaboração própria a partir dos dados do Censo Demográfico 2010 (IBGE, 2010).

46 A tabela 6 resume as características predominantes dos estudantes pendulares de nível superior. Percebe-se que, quanto à categoria administrativa da Instituição de Ensino, a maioria dos estudantes de nível superior frequenta escolas privadas (66,7\%), a idade predominante é a de jovens de 15 a 24 anos (54,5\%), os estudantes de cor ou ração branca representam $64,1 \%$ do total, são predominantemente solteiros $(75,2 \%)$. A maior parte desses estudantes é ocupada (58\%), principalmente no setor educacional (21\%) e $46,8 \%$ são membros de domicílios com renda domiciliar per capita na faixa de um a três salários mínimos.

Tabela 6

Perfil dos estudantes de nível superior - Norte Fluminense - 2010 .

\begin{tabular}{|l|l|l|}
\hline \multicolumn{2}{|l|}{ Ensino Superior } \\
\hline Categoria administrativa & Particular & $66,7 \%$ \\
\hline
\end{tabular}




\begin{tabular}{|l|l|l|}
\hline Grupo de idade & 18 a 24 anos & $54,5 \%$ \\
\hline Cor ou raça & branca & $64,1 \%$ \\
\hline Estado civil & solteiro (a) & $75,2 \%$ \\
\hline Ocupados? & Sim & $58,0 \%$ \\
\hline Setor de atividade & Educação & $21,0 \%$ \\
\hline Rendimento & De 1 a 3 SM & $46,8 \%$ \\
\hline
\end{tabular}

Fonte: Elaboração própria a partir dos dados do Censo Demográfico 2010 IBGE (2010).

\section{Índice de Eficácia da Pendularidade}

Apenas Campos se destaca com IE positivo $(0,59)$, indicando o que se poderia classificar como forte absorção pendular. Todos os demais municípios apresentam IE negativo, indicando saldo migratório negativo. Entre demais municípios com IE negativo, Macaé $(-0,33)$ foi o que apresentou o valor menos elevado, podendo ser considerado como município de média evasão pendular. Os municípios restantes apresentaram valores variando de $-0,66$ a -1 , podendo ser classificados como de forte evasão pendular. 0 município de Cardoso Moreira, não apresentou nenhuma entrada de estudantes de graduação no ano de 2010, somente saídas apresentado um IE de -1,00, como pode ser visto na tabela 7.

Tabela 7

Índice de eficácia da pendularidade, Região Norte Fluminense - 2010.

\begin{tabular}{|l|l|l|l|}
\hline Município & Entrada & Saída & IE \\
\hline Campos dos Goytacazes & 2.389 & 609 & 0,59 \\
\hline Macaé & 645 & 1.284 & $-0,33$ \\
\hline São Fco. Itabapoana & 94 & 454 & $-0,66$ \\
\hline Carapebus & 21 & 258 & $-0,85$ \\
\hline São Fidélis & 25 & 491 & $-0,90$ \\
\hline Quissamã & 13 & 354 & $-0,93$ \\
\hline Conceição de Macabu & 12 & 364 & $-0,94$ \\
\hline São João da Barra & 11 & 601 & $-0,96$ \\
\hline
\end{tabular}




\begin{tabular}{|l|l|l|l|}
\hline Cardoso Moreira & 0 & 278 & $-1,00$ \\
\hline
\end{tabular}

Fonte: Elaboração própria a partir dos dados do Censo Demográfico 2010 IBGE (2010).

Os valores do IE deixam claro que Campos apresenta a maior absorção de estudantes. Porém, cabe ressaltar que Macaé também tem se destacado com relação ao número de matrículas e, consequentemente, atração de estudantes. O município dispõe atualmente de uma cidade universitária onde estão instaladas a Faculdade Municipal Miguel Ângelo da Silva Santos (FeMASS), a UFF e a UFRJ. Além disso, Macaé já dispõe de um campus do Instituto Federal Fluminense (IFF) com cursos técnicos, de graduação e pós graduação e também de um campus da UENF.

O papel de Macaé e seu incipiente polo de educação superior pode ser constado em estudo sobre deslocamentos populacionais publicado em 2015 pelo IBGE. Nesse estudo, o IBGE utilizou os dados de movimento pendular em busca de trabalho e qualificação, além de dados sobre conurbação (contiguidade das manchas urbanizadas) para designar um novo conceito no relacionamento entre dois ou mais municípios, o que denominou de arranjos populacionais.

A noção de integração foi mensurada utilizando: um índice de intensidade relativa dos movimentos pendulares para trabalho e estudo, para cada município, onde a intensidade deve ser igual ou superior a 0,25, denominado índice de integração; ou um valor de intensidade absoluta dos movimentos pendulares para trabalho e estudo, entre dois municípios, igual ou superior a 10000 pessoas; ou uma contiguidade das manchas urbanizadas quando a distância entre as bordas das manchas urbanizadas principais de dois municípios é de até $3 \mathrm{~km}^{17}$.

O resultado dessa mensuração foi a identificação de 294 arranjos populacionais no Brasil, formados por 938 municípios que juntos, representam 55,9\% da população residente no País em 2010. Esses arranjos estão concentrados na Região Sudeste, com 112 unidades, onde foi constatado que, além das metrópoles, os arranjos populacionais acompanham os grandes centros urbanos.

O deslocamento diário de mais de nove mil pessoas chamou a atenção do IBGE que trata como um "caso especial" o arranjo existente entre alguns municípios da Região Norte Fluminense e Baixadas Litorâneas, considerando como formas urbanas a serem acompanhadas no cenário futuro:

O Arranjo de "Macaé - Rio das Ostras/RJ" também possui forte ligação com o do "Rio de Janeiro/RJ", alcançando 12779 pessoas, das quais 81,9\% deslocam-se somente a trabalho. No leste fluminense, as ligações entre o Arranjo de "Macaé Rio das Ostras/RJ" com "Cabo Frio/RJ" e com "Campos dos Goytacazes/RJ" também são significativas, superando 9000 pessoas em cada ligação. Mais especificamente, entre "Macaé - Rio das Ostras/RJ" e "Campos dos Goytacazes/RJ", a ligação é, majoritariamente, para trabalho (86,1\%); com "Cabo Frio/RJ", no entanto, há uma significativa participação do estudo $(26,5 \%)^{18}$.

O arranjo Campos dos Goytacazes - Macaé - Rio das Ostras, é considerado o quinto maior deslocamento (9.010 pessoas), com fluxos diários e de integração populacional do País. Já o arranjo Macaé - Rio das Ostras - Rio de Janeiro, é o segundo maior (13.058), porém bem próximo do primeiro, que é o eixo Rio - São Paulo que apresenta 13.431 pessoas que se deslocam para trabalhar ou estudar.

3 Ainda de acordo com o estudo, 26,5\% das 9.429 pessoas que se deslocam diariamente para Macaé, com origem de Cabo Frio e municípios vizinhos, estão em busca de 
qualificação. Isto equivale a 2.498 pessoas da Região dos Lagos estudando em Macaé. Outrora, esta demanda era em boa parte atendida pelas instituições de ensino de Campos.

Devido ao número expressivo de deslocamentos pendulares entre esses municípios dentro da região Norte Fluminense, o estudo sobre arranjos populacionais sugere ainda que, caso o movimento de pessoas aumente ainda mais entre esses arranjos, poderá configurar uma nova unidade urbana que somaria mais de 1,2 milhão de habitantes. 0 que resultaria na formação de uma região urbana mais complexa, com uma perspectiva regional que vai além dos limites político-administrativos.

\section{Quociente Locacional (QL)}

Os valores calculados para o QL dos municípios da região Norte Fluminense no setor de ensino indicam que o município de Campos dos Goytacazes é o mais especializado no setor educacional, com um QL de 1,545. O município menos especializado é Cardoso Moreira, que apresentou QL de 0,097. Esse resultado evidencia que o setor tem grande importância no município, permitindo que o mesmo exerça papel de polo regional no setor (tabela 8).

Tabela 8

Empregos no setor educacional em valores absolutos e quocientes locacional, Região Norte Fluminense -2010 .

\begin{tabular}{|l|l|l|}
\hline \multirow{2}{*}{ Município } & \multicolumn{2}{|l|}{ Setor Educacional } \\
\cline { 2 - 3 } & Abs. & QL \\
\hline Campos dos Goytacazes & 3.810 & 1,545 \\
\hline Quissamã & 89 & 0,940 \\
\hline São Fidélis & 101 & 0,745 \\
\hline Conceição de Macabu & 47 & 0,734 \\
\hline Macaé & 2.290 & 0,701 \\
\hline São João da Barra & 53 & 0,254 \\
\hline SFI & 9 & 0,133 \\
\hline Carapebus & 8 & 0,123 \\
\hline Cardoso Moreira & 4 & 0,097 \\
\hline Total & 6.411 & - \\
\hline
\end{tabular}

Fonte: Elaboração própria a partir dos dados da RAIS/MTE (2010). 
56 parte da região metropolitana do Rio de Janeiro. Campos, neste contexto, apresenta QL
de 1,21 para o setor educacional, indicando menor nível de especialização no setor de
ensino, quando comparado à escala regional. Como observa-se na figura 5 , Vassouras,
na região Centro-Sul Fluminense é o município mais especializado no setor de ensino,
com QL de 6,29. Trata-se de município de pequeno porte onde desde 1969 existe uma
escola de medicina que evoluiu para a Universidade Severino Sombra. O alto valor do
QL se justifica pela importância dos 1612 vínculos empregatícios no setor de ensino no
total dos 7119 empregos formais do município e a pequena importância do total de
emprego local no total de emprego do estado. O mesmo se pode dizer do QL de
Itaperuna (Noroeste Fluminense), cuja estrutura produtiva é concentrada em empregos
na administração pública, ensino, setor de saúde e comércio e com baixa
representatividade no emprego estadual. Campos, embora apresente importância
relativa no setor de ensino, tem estrutura produtiva e porte populacional mais
relevante no contexto estadual do que vários municípios com QL superior, como pode
ser visto no gráfico da figura 5 , a seguir.

Figura 5

Quociente locacional, setor de ensino, estado do Rio de Janeiro (municípios selecionados) - 2010.

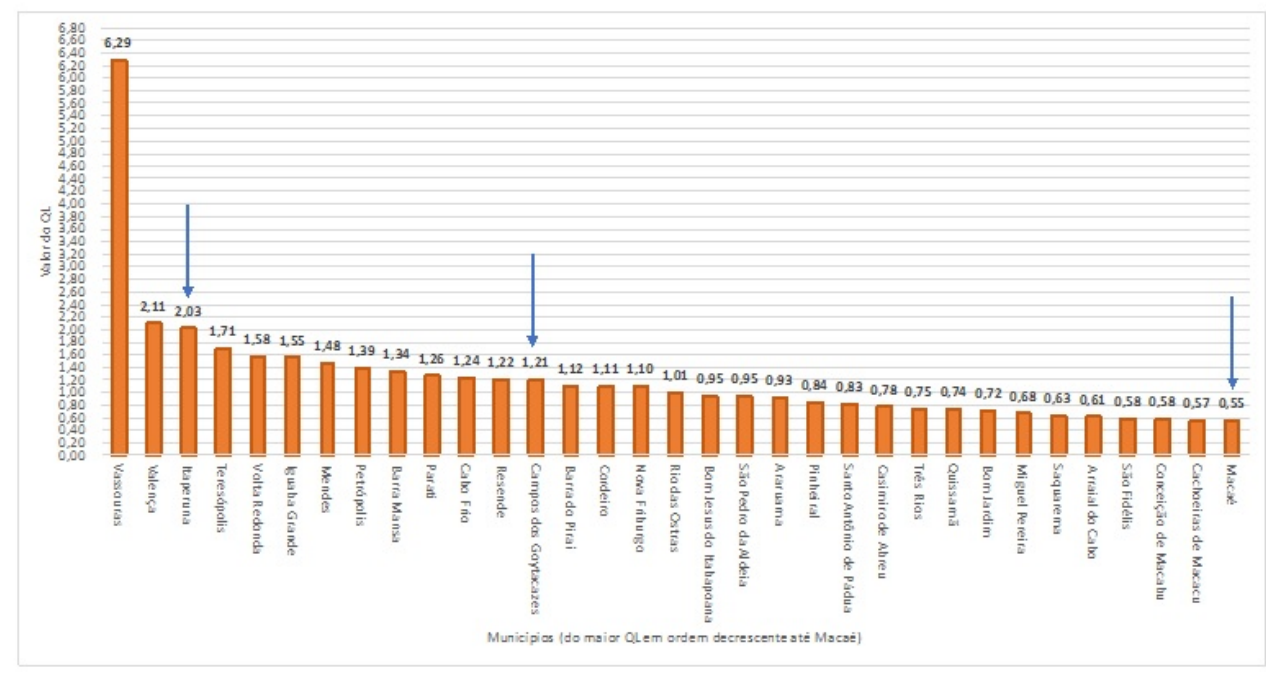

Fonte: Elaboração própria a partir dos dados da RAIS/TEM (2010).

Nota: Os demais municípios não representados nesse gráfico apresentaram QL inferior à 0,55.

Em nível nacional, utilizando-se a categorização dos centros urbanos do IBGE como referência, foram listados 39 municípios que fazem parte da mesma hierarquia urbana de Campos, como capital regional de nível C (tabela 9). Observou-se que a maioria dos municípios (21) apresenta um certo grau de especialização no setor educacional, com QL superior a uma unidade. O estado do Rio de Janeiro conta com apenas dois municípios nesse nível de hierarquia dos centros urbanos: Campos dos Goytacazes e Volta Redonda. Quanto ao QL desses municípios, Campos não apresenta especialização no setor de ensino considerando este recorte territorial, contudo apresentou QL com valor próximo da unidade $(0,93)$, indicando o que se esperava. Ou seja, em uma escala de mesmo nível hierárquico, a tendência é que o QL de todos os municípios não se 
distancie muito da unidade. Levando em conta o QL médio deste conjunto de municípios $(1,02)$, o mediano $(1,01)$ o primeiro quartil $(0,79)$, Campos se insere exatamente entre no intervalo entre os valores $25 \%$ e $50 \%$ dos municípios nesse nível hierárquico.

Tabela 9

Empregos no setor educacional em valores absolutos e quociente locacional, Brasil - Municípios e Estados selecionados por nível de hierarquia urbana (capitais regionais C) - 2010 .

\begin{tabular}{|c|c|c|c|}
\hline \multirow{2}{*}{ Município } & \multirow{2}{*}{ Estado } & \multicolumn{2}{|c|}{ Setor Educacional } \\
\hline & & Abs. & QL \\
\hline Uberaba & MG & 8.020 & 2,08 \\
\hline Mossoró & RN & 4.336 & 1,61 \\
\hline Pelotas & RS & 4.888 & 1,49 \\
\hline Ijuí & RS & 1.258 & 1,44 \\
\hline Presidente Prudente & SP & 4.002 & 1,37 \\
\hline Bauru & SP & 7.224 & 1,32 \\
\hline Araçatuba & SP & 2.749 & 1,26 \\
\hline Pouso Alegre & MG & 2.404 & 1,25 \\
\hline Volta Redonda & RJ & 3.932 & 1,21 \\
\hline Criciúma & SC & 3.291 & 1,17 \\
\hline Santarém & PA & 1.831 & 1,16 \\
\hline Santos & SP & 8.903 & 1,12 \\
\hline Araraquara & SP & 3.531 & 1,12 \\
\hline Ponta Grossa & PR & 3.868 & 1,07 \\
\hline Marília & SP & 2.913 & 1,07 \\
\hline Dourados & MS & 2.384 & 1,06 \\
\hline Teófilo Otoni & MG & 1.177 & 1,05 \\
\hline Juazeiro do Norte & CE & 1.912 & 1,03 \\
\hline Varginha & MG & 1.774 & 1,02 \\
\hline Boa Vista & $R R$ & 3.328 & 1,01 \\
\hline
\end{tabular}




\begin{tabular}{|l|l|l|l|}
\hline Caruaru & PE & 2.758 & 1,00 \\
\hline Arapiraca & AL & 1.213 & 0,96 \\
\hline Campos dos Goytacazes & RJ & 3.810 & 0,93 \\
\hline Araguaína & TO & 1.090 & 0,93 \\
\hline Governador Valadares & MG & 2.300 & 0,91 \\
\hline Petrolina & PE & 2.184 & 0,91 \\
\hline Piracicaba & SP & 4.989 & 0,90 \\
\hline Imperatriz & MA & 1.609 & 0,81 \\
\hline Novo Hamburgo & RS & 2.978 & 0,80 \\
\hline Divinópolis & MG & 2.025 & 0,78 \\
\hline São José dos Campos & SP & 7.091 & 0,73 \\
\hline Sorocaba & SP & 6.020 & 0,72 \\
\hline Barreiras & BA & 815 & 0,70 \\
\hline Ipatinga & MG & 2.603 & 0,69 \\
\hline Macapá & AP & 2.765 & 0,67 \\
\hline Rio Branco & ES & 1.333 & 0,63 \\
\hline Cachoeiro de Itapemirim & 1.142 & 0,58 \\
\hline Sobral & Marabá & 055 & 0,49 \\
\hline
\end{tabular}

Fonte: Elaboração própria dos dados da RAIS/TEM (2010).

\section{Considerações finais}

A indústria petrolífera sediada em Macaé desloca o eixo dinâmico regional de Campos dos Goytacazes para Macaé caracterizando o atual ciclo da economia do Norte Fluminense, baseado na indústria extrativista do petróleo, responsável pela dinâmica econômica da região. Sendo assim a geoeconomia que se desenha é a centralidade de Macaé em termos de localização industrial, com claros reflexos nos municípios vizinhos, a exemplo de Rio das Ostras. Neste contexto, Campos dos Goytacazes assume centralidade na oferta serviços educacionais para qualificação de mão de obra para a indústria petrolífera. 
59 Encontra-se em curso na região, o que poderá inaugurar um novo ciclo na economia regional, os novos empreendimentos como o Complexo Logístico e Industrial do Porto do Açu em São João da Barra e o Complexo Logístico e Industrial Farol-Barra do Furado, nas divisas dos municípios de Campos e Quissamã, podem incentivar o aumento da busca por qualificação para atuar nessas áreas.

60 A consolidação da indústria do petróleo produziu uma competição para localização no espaço regional, enquanto Macaé era lócus privilegiado das empresas da cadeia produtiva da Indústria de Extração e Produção de Petróleo e Gás, Campos consolidou a tradição de polo regional de ensino, tanto superior quanto técnico, ofertado em instituições públicas e privadas.

61 No que tange os deslocamentos populacionais para fins de estudo na região Norte Fluminense, constatou-se herança dos processos históricos na posição do município de Campos dos Goytacazes como centro regional. Apesar do crescente papel do município de Macaé na oferta de ensino superior, as evidências empíricas analisadas dão suporte à uma formulação básica, qual seja: Campos dos Goytacazes é um polo educacional na região Norte Fluminense, atraindo os maiores fluxos de estudantes.

As Instituições de Ensino Superior estão concentradas em poucos municípios, o que faz com que os estudantes se desloquem de seus municípios de residência para cursar o ensino superior. Cabe destacar que, nos deslocamentos para ensino superior, a mobilidade deve mesmo existir uma vez que não se justifica implantar uma instituição de ensino superior em cada município.

o Índice de Eficácia da Pendularidade analisado indicou que a maioria dos municípios da região Norte Fluminense são áreas de forte evasão pendular, apenas o município de Campos do Goytacazes foi classificado como área forte absorção pendular.

o Quociente Locacional reforça o papel de Campos dos Goytacazes como centro regional no que tange a absorção de estudantes, se destacando como o mais especializado no setor educacional em escala regional. Na escala estadual, o QL indicou especialização do município no setor, apesar de não ser o mais especializado. Já em nível nacional, o QL de Campos foi próximo da unidade, demonstrando que o setor tem a mesma importância no município em relação aos municípios do mesmo nível na hierarquia urbana. Esse dado revela que, cada lugar é central em sua respectiva área de influência.

Desse modo, foi demonstrado que os deslocamentos populacionais para fins de estudo na região Norte Fluminense se concentram no município de Campos dos Goytacazes que, apesar de obter baixos índices nas avaliações da educação básica é um polo educacional, principalmente para o ensino superior, exercendo papel de centro regional, atraindo estudantes de várias partes do estado do Rio de Janeiro e, inclusive de outros estados do Brasil.

66 Acrescenta-se que os trabalhos sobre mobilidade populacional para fins educacionais, principalmente em geografia, são relativamente recentes e demandam maiores esforços em pesquisas e análises, uma vez que esses movimentos devem se ampliar em todo território em função da seleção de estudantes de grande parte das IES públicas por meio do Sistema de seleção unificada (SISU). Acrescenta-se ainda que o tema admite uma gama variada de possibilidades analíticas para estudos posteriores, tanto no quadro teórico como na realização de estudos empíricos. Vale ressaltar que a maior parte dos estudos realizados nessa área investigam de forma predominante os movimentos populacionais por motivo de trabalho, embora as magnitudes sejam diferentes, ambos 
seguem lógicas semelhantes, em que a população busca no destino transitório aquilo que o seu lugar de origem não lhe oferece.

\section{BIBLIOGRAFIA}

ANTICO, C.; Deslocamentos Pendulares nos Espaços Sub-regionais da Região Metropolitana de São Paulo. In: Encontro Nacional de Estudos Populacionais, 14., 2004, Caxambu. Anais... Campinas: ABEP, 2004.

BAENINGER, R. Movimentos migratórios no contexto paulista: tendências da década de 80. In: Encontro Nacional de Estudos Populacionais, 10., 1996, Caxambu. Anais... Belo Horizonte: ABEP, 1996. p. 675-704.

BEAUJEU-GARNIER, J. Geografia da população. São Paulo: Companhia Editora Nacional, 1980.

CARVALHO, J. A. M. de; RIGOTTI, J. I. R. Análise das metodologias de mensuração das migrações. In: Encontro Nacional sobre Migração. Anais... Curitiba: Ipardes: FNUAP, 1998. p. 211-227.

CASTELLS, M. (1972). A questão urbana. 3.․ ed. Rio de Janeiro, RJ: Paz e Terra, 2006.

CUNHA, J. M. P. O uso das PNADs na análise do fenômeno migratório: possibilidades, lacunas e desafios metodológicos. Texto para Discussão $n^{\circ} 875$, Rio de Janeiro 2002. IPEA.

CUNHA. Retratos da mobilidade espacial no Brasil: os censos demográficos como fonte de dados. REMHU, Revista Interdisciplinar da Mobilidade Humana. [online]. 2012, vol.20, n.39, p. 29-50.

CUNHA, J. M. P.; JAKOB, A. A. E. ; JIMENEZ, M. A. ; TRAD, I. L. . Expansão metropolitana, mobilidade espacial e segregação nos anos 90: o caso da RM de Campinas. In: CUNHA, J. M. P. (Org.). Novas Metrópoles Paulistas: população, vulnerabilidade e segregação.. 1ed.Campinas: Editora da Unicamp, 2006, v. 1, p. 337-363.

DEMOPÆDIA. Dicionário Demográfico Multilíngue. United Nations. Departement of Economic and Social Affairs. Population Division. International Union for the Scientific Study of Population. 2010. Disponível em: <http://pt-ii.demopaedia.org/wiki/Mobilidade_pendular>. Acesso em: 14 jul. 2015.

FERNANDES, D.; VASCONCELOS I.; Proposta para a inserção da variável migração em sistemas de indicadores municipais. In: encontro nacional de estudos populacionais, 14., 2004, Caxambu. Anais... Campinas: ABEP, 2004.

GIVISIEZ, G. H. N.; OLIVEIRA, E. L.; PIQUET, R. Educação e cidades médias: a nova centralidade de Campos dos Goytacazes - RJ. In: II Simpósio Internacional sobre Cidades Médias Universidade Federal de Uberlândia. Anais... Uberlândia - Minas Gerais - Brasil, nov. 2006. p. 1-16.

GOLGHER, A. B. Fundamentos da migração. Belo Horizonte: UFMG/Cedeplar, 2004.

INSTITUTO BRASILEIRO DE GEOGRAFIA E ESTATÍSTICA (IBGE). Regiões de influência das cidades 2007. Rio de Janeiro: IBGE, 2008. 201 p. Disponível em: <http://www.mma.gov.br/estruturas/ PZEE/_arquivos/regic_28.pdf>. Acesso em: 28 jul. 2015. 
INSTITUTO BRASILEIRO DE GEOGRAFIA E ESTATÍSTICA (IBGE). Arranjos Populacionais e Concentrações Urbanas do Brasil. Rio de Janeiro, 2015. Disponível em: <http://www.ibge.gov.br/ apps/arranjos_populacionais/2015/>. Acesso em: 06 out. 2016.

JARDIM, A. P. Reflexões sobre a mobilidade pendular. In: Reflexões sobre os deslocamentos populacionais no Brasil. OLIVEIRA, L. A. P.; OLIVEIRA, A. T. R. (Orgs.). IBGE. Estudos e Análises, nº1. 2011. p. 58-70.

JARDIM, A. P.; ERVATTI, L. R. Migração pendular intrametropolitana no Rio de Janeiro: a condição de vida das pessoas que trabalham ou estudam fora do município de residência em 1980 e 2000 . In: Encontro Nacional de Estudos Populacionais, 15., 2006, Caxambu. Anais... Belo Horizonte: Associação Brasileira de Estudos Populacionais - ABEP, 2006.

LIMA, W. M. Novas mobilidades, espaço de vida e desempenho escolar: o caso dos estudantes de ensino médio no município de Natal - RN. 2015. 107 f. Dissertação (Mestrado em Demografia) Universidade Federal do Rio Grande do Norte (UFRN), Natal, 2015.

MOURA, R.; BRANCO, M. L. G. C.; FIRKOWSKI, O. L. C. F. Movimento pendular e perspectivas de pesquisas em aglomerados urbanos. São Paulo em Perspectiva [online]. 2005, v.19, n.4, p. 121-133.

PATARRA, N.; CUNHA, J. M. P. Migração um tema complexo. São Paulo em Perspectiva, v. 1, n. 2, p. 32-35, jul/set, 1987.

PEREIRA, R. H. M. Polarização urbana e mobilidade da população: O caso dos deslocamentos pendulares na rede pública de ensino médio do Distrito Federal. In: encontro nacional de estudos populacionais, 15., 2006, Caxambu. Anais... Belo Horizonte: ABEP, 2006.

PEREIRA, R. H. M. Processos sócioespaciais, reestruturação urbana e deslocamentos pendulares na Região Metropolitana de Campinas. 2008. 165 f. Dissertação (Mestrado em Demografia) Instituto de Filosofia e Ciências Humanas, Universidade Estadual de Campinas, Campinas, 2008.

RAVENSTEIN, E. G. The Laws of Migration. Journal of the Statistical Society of London.Vol. 48. No. 2. Jun., 1885. p. 167-235.

\section{NOTAS DE FIM}

1. GIVISIEZ et al. 2006.

2. WUNSCH; TERMOTE, 1978, apud CUNHA, 2012.

3. PATARRA; CUNHA, 1987:32.

4. CUNHA, 2012:47.

5. RIGOTTI, 1998:211

6. ADAN, 1994 apud MOURA et al. 2005:122.

7. JARDIM; ERVATTI, 2006; CUNHA et al., 2006.

8. PEREIRA, 2006:2.

9. DEMOPÆDIA, 2010

10. MOURA et al. 2005:124

11. PEREIRA, 2008; BAENINGER, 1996.

12. JARDIM, 2011:59.

13. CASTELLO BRANCO, 2006 apud IBGE 2008:11.

14. IBGE, 2008:11.

15. REGIC, 2007-IBGE.

16. IBGE, 2012.

17. (IBGE, 2015:9) 
18. (IBGE, 2015:68)

\section{RESUMOS}

O objetivo desse artigo é analisar os movimentos populacionais pendulares em busca de estudos de nível superior na região Norte do Estado do Rio de Janeiro. Enfatizando abordagem predominantemente quantitativa, utilizamos o Censo Demográfico do IBGE de 2010 e o Censo do Ensino Superior do INEP como fontes de dados secundários. Pudemos constatar que os deslocamentos populacionais em tela ocorrem predominantemente em direção a Campos dos Goytacazes, município que, ao exercer papel de centro regional, atrai estudantes de várias partes do estado do Rio de Janeiro e, mesmo, de outros estados do Brasil.

The aim of this paper is to analyse population movements linked to the search for higher education in the northern region of Rio de Janeiro. Stressing the quantitative approach of this text the 2010 IBGE Census is used as primary data source and the Higher Education Census from INEP as secondary data sources. We observed that Campos dos Goytacazes, due to its role as regional centre, is the main destination of these students movements attracting, not only from the Rio de Janeiro, but also from other Brazilian states.

Cet article analyse les rapports entre la mobilité de la population et l'enseignement supérieure au Nord de l'état de Rio de Janeiro. En soulignant une démarche essentiellement quantitative, on utilise le Census Démographique de l'IBGE (2010) et le Census de l'Enseignement Supérieur de l'INEP en tant que sources secondaires. On peut constater que le principal destin de la population c'est la municipalité de Campos dos Goytacazes : en exerçant son rôle de centre régional, elle attire des étudiants pas seulement de l'État de Rio de Janeiro, mais aussi d'autres États brésiliens.

El objetivo de este artículo, es analizar los movimientos poblacionales pendulares en busca de estudios superiores en la región Norte del estado de Rio de Janeiro. El abordaje es principalmente cuantitativo a partir de los datos obtenidos por el censo demográfico do IBGE (Instituto Brasilero de Geografía y Estadística) de 2010 y el censo de enseñanza superior del INEP (Instituto Nacional de Estudios e Investigaciones) como fuente de datos secundarios. Se pudo verificar que los desplazamientos de la población objeto de estudio, ocurren principalmente en dirección a Campos dos Goytacazes, municipio que ejerce como centro regional y atrae estudiantes de varias partes del estado de Rio de Janeiro y también de otros estados de Brasil.

\section{ÍNDICE}

Mots-clés: Mobilité de la population, enseignement supérieur, Nord de l'État de Rio de Janeiro, opportunités d'éducation, Campos dos Goytacazes.

Palabras claves: Movimieno Pendular, enseñanza superior, región de Norte Fluminense, Oportunidades educativas, Campos dos Goytacazes

Keywords: population movements, higher education, North of Rio de Janeiro, educational opportunities, Campos dos Goytacazes.

Palavras-chave: Movimento pendular, ensino superior, região Norte Fluminense, oportunidades educacionais, Campos dos Goytacazes. 


\section{AUTORES}

\section{JÉSSICA MONTEIRO DA SILVA TAVARES}

Mestre em Geografia pela Universidade Federal Fluminense (UFF). Professora de Geografia na Secretaria Estadual de Educação (SEEDUC). E-mail: jessicamonteirost@gmail.com

\section{ELZIRA LUCIA DE OLIVEIRA}

Doutora em Demografia (UFMG). Professora Adjunta IV na Universidade Federal Fluminense (UFF). E-mail: elziralucia@id.uff.br 